OPEN ACCESS

Edited by:

Cristina M. Sena,

University of Coimbra, Portugal

Reviewed by:

Emilio A. Herrera

Universidad de Chile, Chile

Claudia Torres-Farfan,

Universidad Austral de Chile, Chile

*Correspondence:

Xin Sun

sinksunxin@163.com

Yi Yang

doctoryangyi@163.com;

yang_yi@jlu.edu.cn

tThese authors have contributed equally to this work

Specialty section: This article was submitted to Vascular Physiology,

a section of the journal

Frontiers in Physiology

Received: 25 March 2018

Accepted: 30 July 2018

Published: 17 August 2018

Citation:

Guo Z-N, Jin H, Sun H, Zhao Y, Liu J, Ma H, Sun $X$ and Yang $Y(2018)$ Antioxidant Melatonin: Potential Functions in Improving Cerebral

Autoregulation After Subarachnoid Hemorrhage. Front. Physiol. 9:1146.

doi: 10.3389/fphys.2018.01146

\section{Antioxidant Melatonin: Potential Functions in Improving Cerebral Autoregulation After Subarachnoid Hemorrhage}

\author{
Zhen-Ni Guo 1,2t, Hang Jin ${ }^{1 \dagger}$, Huijie Sun ${ }^{3}$, Yingkai Zhao ${ }^{3}$, Jia Liü, Hongyin Ma ${ }^{1}$, Xin Sun ${ }^{1 *}$ \\ and Yi Yang ${ }^{1,2 *}$ \\ ${ }^{1}$ Department of Neurology, The First Hospital of Jilin University, Changchun, China, ${ }^{2}$ Clinical Trial and Research Center \\ for Stroke, Department of Neurology, The First Hospital of Jilin University, Changchun, China, ${ }^{3}$ Cadre Ward, The First \\ Hospital of Jilin University, Changchun, China, ${ }^{4}$ Shenzhen Institutes of Advanced Technology, Chinese Academy \\ of Sciences, Shenzhen, China
}

Subarachnoid hemorrhage $(\mathrm{SAH})$ is a subtype of stroke with high mortality and morbidity. Impaired cerebral autoregulation following SAH has been reported owing to effects on sympathetic control, endothelial function, myogenic response, and cerebral metabolism. Impaired cerebral autoregulation is associated with early brain injury, cerebral vasospasm/delayed cerebral ischemia, and SAH prognosis. However, few drugs have been reported to improve cerebral autoregulation after SAH. Melatonin is a powerful antioxidant that is effective (easily crosses the blood brain barrier) and safe (tolerated in large doses without toxicity). Theoretically, melatonin may impact the control mechanisms of cerebral autoregulation via antioxidative effects, protection of endothelial cell integrity, suppression of sympathetic nerve activity, increase in nitric oxide bioavailability, mediation of the myogenic response, and amelioration of hypoxemia. Furthermore, melatonin may have a comprehensive effect on cerebral autoregulation. This review discusses the potential effects of melatonin on cerebral autoregulation following $\mathrm{SAH}$, in terms of the association between pharmacological activities and the mechanisms of cerebral autoregulation.

Keywords: melatonin, cerebral autoregulation, subarachnoid hemorrhage, antioxidant, sympathetic nerve, endothelial function

\section{INTRODUCTION}

Cerebral autoregulation is defined as the mechanism by which constant cerebral blood flow is maintained, despite changes in arterial blood pressure (Guo et al., 2016). In the cerebral arterial system, cerebral autoregulation has been reported to be involved in all types of stroke and is related to secondary brain injury and prognosis (Vavilala et al., 2003; Chen et al., 2014b; Guo et al., 2014; Ma et al., 2016). In the reviews of Paulson and Strandgaard in 1984 and 1990, they concluded that the regulating mechanisms of cerebral autoregulation are including sympathetic control, cerebral metabolism, endothelial function and myogenic response (Strandgaard and Paulson, 1984; Paulson et al., 1990). Later, Bailey proposed that oxidative stress is also associated with impaired cerebral autoregulation and blood-brain barrier leakage (Bailey et al., 2011).

Subarachnoid hemorrhage (SAH) is a subtype of stroke with high mortality and significant morbidity. Delayed cerebral vasospasm and delayed cerebral ischemia are among the primary causes of poor prognosis following SAH. Cerebral autoregulation has been reported to be 
impaired after SAH, and this phenomenon is associated with cerebral vasospasm/delayed cerebral ischemia (Budohoski et al., 2012, 2013; Otite et al., 2014; Calviere et al., 2015; Guo et al., 2016; Santos et al., 2016; Gaasch et al., 2018). Thus, cerebral autoregulation may be a potential therapeutic target for improving prognosis after $\mathrm{SAH}$.

Melatonin is a hormone secreted by the pineal gland during the dark phase of the light-dark cycle, which is modulated by light-dark cycle (Bruls et al., 2000). Besides the pineal gland, melatonin was also produced in bone marrow (Tan D.X. et al., 1999). In addition, Tan D. et al. (1999) found high levels of melatonin in the bile of mammals of unknown origin. Previous studies reported that melatonin is a powerful antioxidant, which is known to be effective (it easily crosses the blood brain barrier) and safe (non-toxic in high doses) (Reiter et al., 2000). It has been studied in several cerebrovascular diseases, including ischemic stroke (Beker et al., 2015; Feng et al., 2017), intracerebral hemorrhage (Li et al., 2009; Lekic et al., 2010), and SAH (Table 1) (Fang et al., 2009; Wang et al., 2012, 2013; Chen et al., 2014a,c, 2015; Dong et al., 2016; Zhao et al., 2016), with respect to the mechanisms of antioxidation (Garcia et al., 2014; Zhang and Zhang, 2014; Manchester et al., 2015) and anti-inflammation (Agil et al., 2013; Mauriz et al., 2013; Chen et al., 2014a; Yang et al., 2014; Liu et al., 2015; Dong et al., 2016). These pharmacological activities of melatonin also potentially improve cerebral autoregulation after SAH. The present review discusses the potential effect of melatonin on cerebral autoregulation after $\mathrm{SAH}$ with respect to the association between pharmacological activities and mechanisms regulating cerebral autoregulation.

\section{CEREBRAL AUTOREGULATION DYSFUNCTION AFTER SAH}

\section{Clinical Findings}

Recently, an increasing number of studies have focused on the relationship between cerebral autoregulation and SAH and have reported that the impairment of cerebral autoregulation is related to poor prognosis after SAH. Otite et al. (2014) reported that patients who developed delayed cerebral vasospasm and delayed cerebral ischemia after SAH had worse cerebral autoregulation than did those who did not develop either of the conditions. Budohoski et al. (2015) conducted a study to determine the underlying consequences of unilateral and bilateral cerebral autoregulation damage on outcomes in SAH patients. They found that unilateral and bilateral cerebral autoregulation damage was related to delayed cerebral ischemia and unfavorable outcomes, respectively (Budohoski et al., 2015). Santos et al. (2016) analyzed the pathophysiological basis of the impairment of cerebral autoregulation in SAH and its relationship to prognosis. They found that cerebral autoregulation was significantly impaired in SAH patients who developed delayed cerebral ischemia compared with those who did not develop secondary brain injury or cerebral vasospasm alone (Santos et al., 2016). Similar results were reported by several studies (Table 2) (Lang et al., 2001; Soehle et al., 2004; Tseng et al., 2006; Budohoski et al., 2012, 2013, 2016; Calviere et al., 2015; Gaasch et al., 2018).

\section{Mechanisms}

Impaired cerebral autoregulation after SAH is possibly caused by oxidative stress, endothelial dysfunction, sympathetic activation, myogenic response disorder, and abnormal cerebral metabolism. A detailed study of these mechanisms might lead to future therapeutic possibilities.

\section{Oxidative Stress After SAH}

After SAH, oxidative stress is implicated in the etiology of at all stages of SAH (early brain injury, cerebral vasospasm, and delayed cerebral ischemia) (Ersahin et al., 2010; Zhang et al., 2015; Li et al., 2016; Ye et al., 2018). The high concentration of reactive oxygen species (ROS)/reactive nitrogen species (RNS) is considered to be associated with impaired cerebral autoregulation (Choi et al., 2001; Shin et al., 2002) (Figure 1). One important mechanism has been reported to result in impaired cerebral autoregulation is because of the direct and indirect actions of ROS/RNS on $\mathrm{K}+$ channels. The $\mathrm{K}+$ channels, including ATP-sensitive $\mathrm{K}+$ channels and large conductance $\mathrm{Ca}^{2+}$-activated $\mathrm{K}^{+}$channels, can regulate the activation and contraction of cerebral arterial muscle cells, and subsequently change the smooth muscle tone (Lee et al., 1993; Nelson and Quayle, 1995; Shin and Hong, 2004; Zagorac et al., 2005). Moreover, the high concentration of free radicals may cause impaired cerebral autoregulation in several other pathways, including damaged endothelial cells function (followed by integrity destroyed and nitric oxide availability reduced), and inducted inflammatory response (followed by endothelial cells dysfunction and hypoxemia condition). These factors are discussed in the following sections (Figure 1).

\section{Endothelial Dysfunction After SAH}

The vascular endothelial mechanism is an essential part of cerebral autoregulation because endothelial cells modulate many aspects of vascular functioning, particularly in controlling the vascular tone (Pries et al., 2000; Rodella et al., 2013). The structural and functional integrity of endothelial cells is essential for maintaining stable cerebral autoregulation (Preckel et al., 1996; White et al., 2000; Ainslie et al., 2007; Guo et al., 2016). After SAH, both structural and functional integrity were damaged because of factors, such as the high concentration of ROS/RNS and inflammatory responses (Figure 1) (Kajita et al., 1998; Scharbrodt et al., 2009; Szatmari et al., 2010; Sabri et al., 2011; Qin et al., 2012; Liu et al., 2016; de Azevedo et al., 2017; Shekhar et al., 2017; Armstead et al., 2018). In inflammatory responses, various inflammatory pathways, such as the NF- $\kappa$ B pathway (Pawlowska et al., 2018), NLRP3 pathway (Li et al., 2016; Shao et al., 2016), and TLR4 pathway (Zhang et al., 2016), are activated and have negative effects on the arterial endothelium after SAH. In the downstream of these pathways are inflammatory factors, interleukin- $1 \beta$, and tumor necrosis factor$\alpha$. These inflammatory factors act on vascular endothelium, resulting in changes in the concentration and bioavailability of endothelium-derived nitric oxide.

Nitric oxide, the most important vasodilation factor, can regulate the vascular tone of small arteries; the mechanism is that nitric oxide diffuses into the adjacent smooth muscle cells 
TABLE 1 | Functions of melatonin in improving brain injury after subarachnoid hemorrhage.

\begin{tabular}{|c|c|c|c|}
\hline Journal & First author & Year & Action targets \\
\hline J Pineal Res & Dong $Y$ & 2016 & Regulating NLRP3 inflammasome and apoptosis signaling. \\
\hline Mol Neurobiol & Zhao L & 2016 & Regulating melatonin receptor/Sirt1/NF-кB signaling pathway \\
\hline J Pineal Res & Chen J & 2014 & Regulation of pro-inflammatory cytokines \\
\hline J Pineal Res & Chen J & 2014 & Regulating mitochondrial pathway \\
\hline J Pineal Res & Wang Z & 2013 & Regulating TLR4-mediated inflammatory pathway \\
\hline J Pineal Re & Wang Z & 2012 & Activating the Nrf2-ARE pathway \\
\hline Mediators Inflamm & Fang Q & 2009 & Regulating nuclear factor-kappa pathway and proinflammatory cytokines expression \\
\hline
\end{tabular}

TABLE 2 | Literature on cerebral autoregulation (CA) and subarachnoid hemorrhage in humans.

\begin{tabular}{|c|c|c|c|}
\hline Journal & First author & Year & Main outcomes \\
\hline Crit Care Med & Gaasch M & 2018 & CA was associated with delayed cerebral ischemia (DCl) and poor functional outcome \\
\hline Neurology & Santos GA & 2016 & CA can predict neurologic complications \\
\hline Acta Neurochir Suppl & Budohoski KP & 2016 & Impaired $\mathrm{CA}$ in the first 5 days after $\mathrm{SAH}$ is predictive of $\mathrm{DCl}$ \\
\hline Neurocrit Care & Calviere L & 2015 & Early deterioration of CA was strongly predictive of $\mathrm{DCl}$ \\
\hline Neurocrit Care & Budohoski KP & 2015 & $\begin{array}{l}\text { Unilateral CA failure was seen in patients who developed DCI, and bilateral CA failure was seen } \\
\text { more frequently in patients with unfavorable outcome }\end{array}$ \\
\hline Stroke & Otite F & 2014 & Impaired CA is associated with vasospasm and $\mathrm{DCl}$ \\
\hline J Cereb Blood Flow Metab & Budohoski KP & 2013 & CA can aid in predicting $\mathrm{DCl}$ \\
\hline Stroke & Budohoski KP & 2012 & Disturbed CA in the first 5 days after SAH significantly increases the risk of $\mathrm{DCl}$ \\
\hline Neurosurg Focus & Tseng MY & 2006 & CA may help identify patients at high risk of delayed ischemic neurological deficits. \\
\hline Anesth Analg & Soehle M & 2004 & CA was impaired during cerebral vasospasm \\
\hline Crit Care Med & Lang EW & 2001 & CA impairment precedes vasospasm, and ongoing vasospasm worsens CA \\
\hline
\end{tabular}

and relaxes them by increasing cyclic guanosine monophosphate (Kajita et al., 1998). Because of the physiological effects of nitric oxide, Guo et al. (2016) proposed that reduced nitric oxide availability may relate to the impaired cerebral autoregulation after SAH due to endothelium-dependent mechanism. The results reported by Tseng et al. (2005) support this hypothesis; these authors found that pravastatin, a member of the drug class of statins, can improve vascular endothelium-dependent relaxation to acetylcholine and increase endothelial nitric oxide synthase activity, as well as improve cerebral autoregulation after SAH (Tseng et al., 2005; Yamamoto et al., 2007). Thus, these studies indicated that the improvement in endothelial function is a therapeutic target to improve cerebral autoregulation.

\section{Sympathetic Activation After SAH}

The cerebrovascular bed is innervated by sympathetic nerve fibers (Edvinsson et al., 1975; Hamner et al., 2010). The sympathetic nervous system regulates cerebral blood flow by managing cerebral vascular resistance (Aubineau et al., 1980; Busija, 1985; Guo et al., 2016). Theoretically, after the stimulation of sympathetic nervous system, alpha-1 adrenergic receptors are activated by norepinephrine released by postganglionic sympathetic neurons, resulting in vasoconstriction (Aubineau et al., 1980; Busija, 1985; Guo et al., 2016). Several studies have reported that sympathetic control plays an important role in regulating cerebral autoregulation, and that sympathetic dysfunction can cause impaired cerebral autoregulation (Sadoshima et al., 1985; Hamner and Tan, 2014; Guo et al., 2016). Notably, the acute stage of SAH is accompanied by significant sympathetic activation (Moussouttas et al., 2012b, 2014). Sympathetic activation results in increased concentration of circulating catecholamines (epinephrine, noradrenaline, and serotonin), which are associated with cerebral vasospasm and delayed cerebral ischemia after SAH (Grad et al., 1991; Dilraj et al., 1992; Naredi et al., 2000; Banki et al., 2005; Moussouttas et al., 2012a). The vasoconstriction of blood vessels caused by sympathetic activation after SAH is a possible mechanism underlying cerebral autoregulation dysfunction (Figure 1).

\section{Myogenic Response Disorder After SAH}

Smooth muscle is a main component of cerebral arteries. The control of arterial myogenic tone was first described by Bayliss (1902). The myogenic response was regulated by a complex mechanism, and some of these mechanisms are out of balance after SAH (Lidington et al., 2018). (1) Previous study reported that potassium channels are important regulators of vascular tone. SAH can reduce potassium currents in cerebral artery smooth muscle cells and then enhanced constriction (Jahromi et al., 2008). (2) After SAH, endothelial dysfunction was observed, resulting in reduced vasodilating factors levels. Thus, it is reasonable to speculate that endothelial dysfunction augments myogenic response disorder (Lidington et al., 2018). (3) The effect of ROS on myogenic response disorder was our concern. ROS are believed to be involved in cellular signaling in blood vessels, and to directly and indirectly mediate vascular smooth muscle via regulating endotheliumdependent contractions pathway (Cosentino et al., 1994), and calcium-activated potassium channels (Wei et al., 1996; Faraci, 

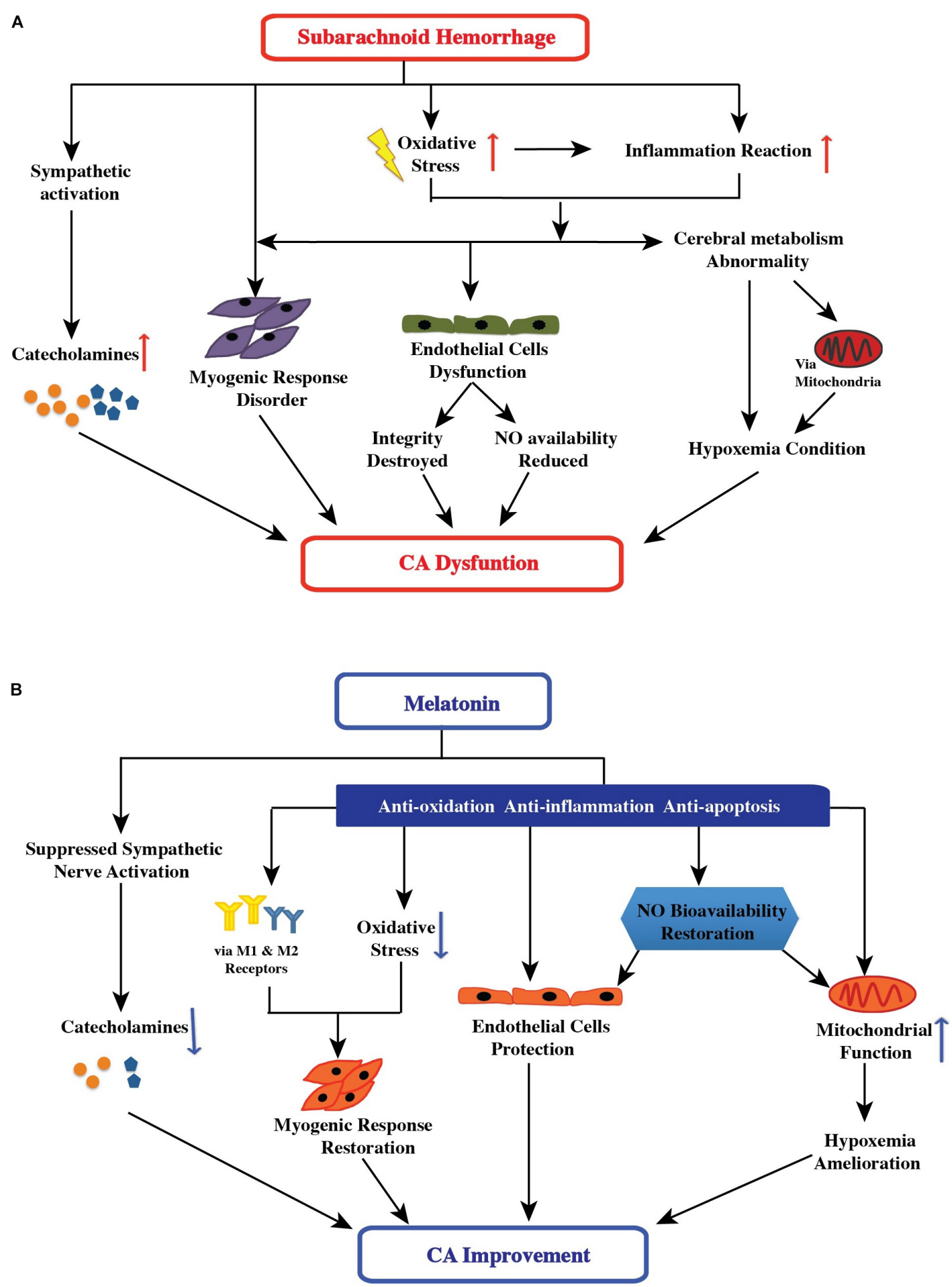

FIGURE 1 | (A) Effect of subarachnoid hemorrhage on the control mechanisms of cerebral autoregulation. After subarachnoid hemorrhage, oxidative stress is implicated in the etiology of all stages: the high free-radical concentration leading to impaired cerebral autoregulation has direct and indirect effects, including changing smooth muscle tone, damaging endothelial cell function (followed by destruction of endothelial cell integrity and reduction of nitric oxide availability), and inducing an inflammatory response (followed by endothelial cell dysfunction and hypoxemia). Additionally, sympathetic activation and abnormal cerebral metabolism after SAH aggravated the impairment of cerebral autoregulation. (B) Possible therapeutic targets of melatonin in improving cerebral autoregulation after subarachnoid hemorrhage. After subarachnoid hemorrhage, melatonin may potentially impact the control mechanisms of cerebral autoregulation via suppression of sympathetic nerve and antioxidant activity, increase in nitric oxide bioavailability, direct and indirect mediation of the myogenic response, and amelioration of hypoxemia. Furthermore, melatonin can have a comprehensive effect on cerebral autoregulation. 
2006). Previous studies also reported that both relaxation and contraction of the vascular muscle were caused by ROS, which may dependent on concentrations (Faraci, 2006). For instance, Rosenblum found that the generation of superoxide using acetaldehyde and xanthine oxidase produces dilation of cerebral arterioles at low substrate concentrations, but vasoconstriction at higher substrate concentrations followed by dilation (Rosenblum, 1983). Studies in vivo found that hydrogen peroxide acts as a vasodilator on small cerebral arteries via activated potassium channels. However, high concentrations of hydrogen peroxide can produce vasoconstriction followed by vasodilation (Faraci, 2006). The general trend is that, ROS produces vasodilation at low concentrations and vasoconstriction at higher concentrations (Rosenblum, 1983; Cosentino et al., 1994; Wei et al., 1996; Faraci, 2006). Thus, high concentration of ROS (derived from blood) may augment the myogenic tone via directly and indirectly mediate vascular smooth muscle after SAH. Recently, a study from Deng et al. (2018) provided direct evidence. They studied the effects of extravascular hemolyzed blood on arteriolar myogenic constriction and found that extravascular hemolyzed blood augments the myogenic constriction of cerebral arterioles, possibly by increasing the vascular production of superoxide. In addition to ROS pathways, a study reported that tumor necrosis factor- $\alpha$ /sphingosine-1-phosphate signaling can augment the myogenic tone in experimental SAH mouse model (Yagi et al., 2015). These studies indicated that the effects of the myogenic response on cerebral autoregulation may be caused multiple pathways and need further analysis.

\section{Metabolism Abnormal Impaired Cerebral Autoregulation After SAH}

Under physiological conditions, when the cerebral blood volume was decreased, some vasoactive substances were released from the brain, caused the cerebral arteries to become dilated, and vice versa. This phenomenon was considered a metabolic mechanism of cerebral autoregulation to maintain stable cerebral perfusion. Actually, apart from vasoactive substances, oxygen and carbon dioxide levels and metabolites can regulate cerebral autoregulation. After $\mathrm{SAH}$, the reduced brain tissue oxygen pressure and brain $\mathrm{pH}$ (Carvi y Nievas et al., 2005) can change cerebral microcirculation and metabolism, perhaps partly because of oxidative damage (Lopez et al., 2009). These changes may cause cerebral autoregulation dysfunction (Figure 1).

\section{THE ROLE OF MELATONIN IN IMPROVING CEREBRAL AUTOREGULATION AFTER SAH}

\section{Melatonin Improves Cerebral Autoregulation by Antioxidation}

Previous studies have found that melatonin and its metabolites (mainly $N^{1}$-acetyl- $N^{2}$-formyl-5-methoxykynuramine and $\mathrm{N}$-acetyl-5-methoxykynuramine) are powerful free radical scavengers, and scavenge various types of free radicals, such as hydroxyl radicals and hydrogen peroxide. Through a cascade reaction involving melatonin and its metabolites, a melatonin molecule can scavenge up to 10 ROS/RNS (Tan et al., 2002; Zavodnik et al., 2006; Hardeland et al., 2007; Tan et al., 2007). Besides, Boussard et al. (2006) reported that the third melatonin binding site (MT3), characterized as the enzyme quinone reductase 2 , may contribute to melatonin antioxidant properties by inhibiting the electron transfer reactions of quinones (Boussard et al., 2006; Pandi-Perumal et al., 2008; Emet et al., 2016).

In addition, melatonin plays an important role in activating antioxidant defenses. Venkataraman et al. (2010) found that exogenous melatonin supplementation can rescue the decreased mRNA expression of $\mathrm{Cu} / \mathrm{Zn}$ superoxide dismutase and glutathione peroxidase- 4 in a polychlorinated biphenylinduced neuronal damage rat model. Akcay et al. (2005) reported that treatment with exogenous melatonin can maintain malondialdehyde levels and catalase and superoxide dismutase activities at normal levels in the brain cortex of a kainic acidinduced injury rat model. Moreover, melatonin can inhibit pro-oxidant enzymes, such as inducible nitric oxide synthase (Lopez et al., 2006; Kang et al., 2013).

Thus, melatonin is a useful antioxidant, and acts via multiple antioxidant pathways; its antioxidative actions directly and indirectly improve cerebral autoregulation by protecting endothelial function and increasing nitric oxide bioavailability, mediating myogenic responses, and ameliorating conditions of hypoxemia. This is discussed in the following sections.

\section{Melatonin Improves Cerebral Autoregulation by Protecting Endothelial Function and Increasing Nitric Oxide Bioavailability}

As mentioned above, melatonin serves as an antioxidant via several pathways. It also has anti-inflammatory effects. Several studies have reported the possible pathways through which melatonin attenuates inflammation in the brain (Carrascal et al., 2018; Wang et al., 2018). Jumnongprakhon et al. (2016) found that melatonin can prevent methamphetamineinduced inflammatory responses by inhibiting the nuclear factor$\kappa \mathrm{B}$ pathway and promoting the nuclear factor erythroid 2related factor-2 pathway before blood-brain barrier impairment. Dong et al. (2016) suggested that melatonin regulates the NLRP3 inflammasome pathway, and thus attenuates early brain injury after SAH. Wang et al. (2013) proposed that melatonin can alleviate secondary brain damage through the TLR4mediated inflammatory pathway after SAH. Fu et al. (2017) also reported that melatonin supplementation may be a valuable therapeutic strategy in cases of inflammatory neurological dysfunction, and that melatonin may subserve this function through the inhibition of TLR4 signaling. Zhao et al. (2015) reported that melatonin attenuates sepsis-induced brain injury by activating silent information regulator 1 signaling (Zhao et al., 2015). In addition, oxidative stress plays a vital role in mediating the initial phase of the inflammatory reaction by regulating leukocyte recruitment and maturation and activating intracellular inflammatory pathways, resulting in increased 
levels of various inflammatory mediators (Cristofanon et al., 2009; Radogna et al., 2010). Melatonin can regulate signaling through these pathways and thus inhibit inflammatory processes (Figure 1).

Previous studies have reported that melatonin functions to increase nitric oxide bioavailability. Aladag et al. (2009) conducted a study in an SAH rat model and showed that the administration of melatonin ameliorates cerebral vasospasm via an increase in serum nitric oxide concentration and a decrease in the levels of arginase and oxidative stress in the brain. Similarly, using intermittent hypoxia rat models, Tjong et al. (2008) showed that melatonin ameliorates constitutive nitric oxide production and large conductance calcium-activated potassium channel activity through an antioxidant pathway. Wakatsuki et al. (2001) studied the antioxygenation effect of melatonin on the oxidized low-density lipoprotein-induced impairment of nitric oxide production, and found that pretreatment with melatonin reversed the oxidized low-density lipoprotein-induced reduction in nitric oxide production. In their review, Simko and Paulis noted that melatonin may increase nitric oxide levels via the promotion of nitric oxide production and/or the prevention of coupling to the superoxide anion radical (Simko and Paulis, 2007). However, some studies have reported that melatonin reduces nitric oxide levels in middle cerebral artery occlusion stroke rat models (Pei et al., 2003) and cerebral ischemia/reperfusion Mongolian gerbil models (Guerrero et al., 1997). Thus, the role of melatonin in nitric oxide production requires further investigation.

Previous studies show that melatonin can act as an endothelial protective agent via the disruption of oxidative stress and inflammatory response pathways and may also regulate nitric oxide concentration and bioavailability. Thus, it can protect the integrity and function of vascular endothelial cells.

\section{Melatonin Improves Cerebral Autoregulation by Suppressing Sympathetic Nerve Activity}

In previous studies, melatonin has been shown to regulate sympathetic nerve activity. Viswanathan et al. (1986) found that the administration of melatonin to Syrian hamsters suppressed the sympathetic nervous system. Cagnacci et al. (1998) found that the administration of melatonin decreased blood pressure and blunt noradrenergic activation in young women. Arangino et al. (1999) reported that oral administration of melatonin could reduce blood pressure, vascular reactivity, and norepinephrine levels in men. Girouard et al. (2004) found that exogenous melatonin improved the baroreflex response associated with improved antioxidation in spontaneously hypertensive rats, suggesting a correlation between antioxidation and the decreased sympathetic tone induced by melatonin. In another study of spontaneously hypertensive rats, K-Laflamme et al. (1998) found that after $20 \mathrm{~min}$ of melatonin administration, the plasma epinephrine concentration reduced by approximately $60 \%$, and the norepinephrine concentration decreased by approximately $30 \%$. This indicated that the action of melatonin involved the inhibition of basal sympathoadrenal tone (KLaflamme et al., 1998). Interestingly, Olmez and Kurcer (2003) found that melatonin can attenuate alpha-adrenergic-induced contractions by increasing vasoactive intestinal peptide levels in isolated rat penile bulbs. In addition, several studies have found that melatonin can affect the neural control of reflex changes in muscles and sympathetic nerve activity in the skin (Ray, 2003; Muller et al., 2013). Hence, the role of melatonin in regulating sympathetic nerve activity is gradually becoming clearer. However, these evidences of melatonin in regulating sympathetic nerve activity is based on systemic effects, we also tried to find direct evidence of melatonin on cerebral regulation. After careful searching, only one study was found. Bang et al. (2012) reported that exogenous melatonin did not affect the cardiovascular reflex and dynamic cerebral autoregulation responses to acute hypotension in twelve healthy men. The reason for the negative results may due to the subjects were healthy adults and the sample size was too small. Thus, theoretically, melatonin may be a potentially useful drug for improving cerebral autoregulation via a reduction in sympathetic nerve activity after SAH (Figure 1), but the actual effect of melatonin remains to be studied.

\section{Melatonin Improves Cerebral Autoregulation by Mediating Myogenic Response}

As mentioned in the previous section, the ROS concentration may play an important role in regulating vasomotor function after SAH. Melatonin acts as a powerful ROS scavenger, functioning to mediate myogenic responses after SAH. In addition, exogenous melatonin reduces the concentration of tumor necrosis factor- $\alpha$ in the brain (Pazar et al., 2016; Taniguti et al., 2018), and may thus reduce tumor necrosis factor$\alpha$-mediated myogenic tone augmentation (Yagi et al., 2015). Weekley (1991) reported that melatonin induces the dosedependent relaxation of precontracted vascular smooth muscle of rat aorta, and this response was not affected by vascular endothelium removal.

Furthermore, melatonin can have direct effects on smooth muscle through its receptors. Humans have two plasma membrane receptors of melatonin, MT1 and MT2, which are expressed in various tissues, including brain, retina, cardiovascular system, and liver tissues (Ekmekcioglu, 2006). MT1 and MT2 belonging to the G-protein-coupled receptor superfamily, which constitutes adenylate cyclase inhibition by binding to various G-proteins (Pandi-Perumal et al., 2008; Emet et al., 2016). In the central nervous system in humans, melatonin receptors are observed in suprachiasmatic nuclei (Weaver and Reppert, 1996), retina (Reppert et al., 1995; Thomas et al., 2002; Ekmekcioglu, 2006), hippocampus (Savaskan et al., 2002; Savaskan et al., 2005), and cerebellar cortex (Al-Ghoul et al., 1998). In studies on the caudal artery, the MT1 receptor mRNA was primarily found in the smooth muscle layer, whereas the MT2 receptor mRNA appeared more evenly distributed throughout the vessel wall. However, 
both MT1 and MT2 in vascular smooth muscle cells can regulate the vascular tone. Doolen et al. (1998) indicated that MT1 receptor activation may mediate vasoconstriction. Subsequently, Lew and Flanders (1999) further indicated that melatonin elicited the contraction of the rat tail artery by activating an MT1 receptor that coupled to the activated L-type calcium channels. For the MT2 receptor, study conclusions are inconsistent. Masana et al. (2002) indicated that after using MT2 antagonists, the melatonin-mediated vasocontraction was enhanced, indicating MT2 receptors located in vascular smooth muscle mediate vasodilation. Similarly, Doolen et al. (1998) also found MT2 receptors may induce relaxation. However, a study reported that MT2 receptor activation in coronary vascular smooth muscle cells is associated with inhibiting nitric oxide-induced increases in cyclic GMP and coronary arterial relaxation (Tunstall et al., 2011). The comprehensive effects of melatonin receptors in regulating the myogenic response warrants further studies. There are also studies of the effect of melatonin on cerebral arteries. Régrigny et al. (1999) found that melatonin can induce the increase of cerebral arteriolar tone via stimulating MT1 and/or MT2 receptors followed by blockade of calcium-activated large conductance potassium channels in rats, they also reported that melatonin decreased the lower limit of cerebral blood flow autoregulation, which may potential reduce the risk of hypoperfusion-induced cerebral ischemia. Later, Lapi et al. (2011) studied the rat pial microvascular responses induced by melatonin during brain hypoperfusion and reperfusion injury. They found melatonin can regulate the pial arteriolar tone and then promote an efficient redistribution of microvascular blood flow via activating MT1 and MT2 receptors, they further reported that lower dosage of melatonin stimulate MT2 receptors, while higher dosage activated also MT1 receptors (Lapi et al., 2011). From the above two studies, we can speculate that melatonin may have neuroprotective effect via regulating myogenic response of cerebral arteries.

\section{Melatonin Improves Cerebral Autoregulation by Ameliorating Hypoxemia and Regulating Metabolism}

To ameliorate hypoxemia, mitochondrial function is crucial. Melatonin can protect mitochondrial functioning through its anti-apoptosis, antioxidative, and combined anti-apoptosis and antioxidative effects. Lopez et al. (2009) have indicated that melatonin protects mitochondria from damage due to oxidative stress by reducing oxygen consumption, membrane potential, and superoxide anion production. Carretero's study presents the same conclusions (Carretero et al., 2009). Yamamoto and Mohanan concluded that melatonin protects against attenuated brain mitochondrial DNA damage induced by hydroxyl radicals (Yamamoto and Mohanan, 2002). In addition, Xu et al. (2016) found that melatonin potentials protects against cadmium neurotoxicity by blocking calcium-dependent translocation of Drp1 to the mitochondria. Recently, a study by Sinha et al. (2018) further reported that melatonin can inhibit mitochondrial cell death pathways by upregulating the MT1 receptor in newborn hypoxic-ischemic brain injury mice models. Besides improving the mitochondrial function, melatonin reportedly can act on cerebral nitric oxide/nitric oxide synthase after hypobaric hypoxia injury, which balances the release of nitric oxide, reduces peroxynitrite formation, and protects against nitrosative/oxidative damage (Blanco et al., 2017).

Thus, the collective general findings were that melatonin protects against hypoxemia. Although it is unknown whether melatonin can improve cerebral autoregulation after $\mathrm{SAH}$ by ameliorating the reduced brain-tissue oxygen pressure and brain $\mathrm{pH}$, there is a theoretical basis for this hypothesis (Figure 1). It is worth mentioning that a study conducted by Herrera et al. (2014) found that, in chronically hypoxic lambs, melatonin improved vascular responses to potassium, serotonin, and methacholine and enhanced the endothelial response via nitric oxide-independent mechanisms in isolated arteries. This study indirectly indicates the possible impact of melatonin on cerebral autoregulation (Herrera et al., 2014).

\section{Comparison of Melatonin With Other Medications in Improving Cerebral Autoregulation}

Previous studies have reported that several medications may have the potential to improve cerebral autoregulation after SAH. Nitric oxide plays an important in regulating cerebrovascular tone by maintaining the dilation of the vasculature. After SAH, nitric oxide production and responses to endothelium-dependent vasodilators were impaired owing to injury to the cerebrovascular endothelium, resulting in vasoconstriction (Sobey and Faraci, 1998). Consequently, nitric oxide (or nitric oxide donors) was proposed as a possible medication to improve cerebral autoregulation after SAH (Guo et al., 2016). In contrast to melatonin, nitric oxide improves cerebral autoregulation by activating calcium-dependent potassium channels in vascular smooth muscle, thus maintaining stable vascular tone after SAH.

Vasoactive substances can act on vascular smooth muscle, leading to cerebral arterial vasoconstriction or vasodilation. Some vasoactive substances, such as norepinephrine, adrenomedullin, and indomethacin, may have protective functions in cerebral autoregulation (Armstead et al., 2010a, 2016; Chock et al., 2012). However, no such protective function has been reported for other vasoactive substances, such as sodium nitroprusside (Armstead et al., 2010b; Baerts et al., 2013). It is notable that, unlike that for melatonin, the dose of vasoactive substances should be carefully monitored, as the impact of these drugs on cerebral autoregulation may vary based on the dose.

Additionally, pravastatin was reported has the function to improve cerebral autoregulation after SAH by improving vascular endothelium-dependent relaxation in response to acetylcholine, increasing endothelial nitric oxide synthase activity, and enhancing the vascular protective effects of Olmesartan (Yamamoto et al., 2007). These mechanisms have 
similarities and dissimilarities to the mechanisms of the action of melatonin. Additionally, we attempted to identify more antioxidants that have been reported to have effects on cerebral autoregulation, but failed to find any further evidence.

\section{CONCLUSION}

Melatonin potentially impacts the control mechanisms of cerebral autoregulation after SAH through antioxidation, protection of endothelial cell integrity, suppression of sympathetic nerve activity, increase in nitric oxide bioavailability, mediation of the myogenic response, and amelioration of hypoxemia. Furthermore, melatonin may have a comprehensive effect on cerebral autoregulation after SAH.

\section{REFERENCES}

Agil, A., Reiter, R. J., Jimenez-Aranda, A., Iban-Arias, R., Navarro-Alarcon, M., Marchal, J. A., et al. (2013). Melatonin ameliorates low-grade inflammation and oxidative stress in young Zucker diabetic fatty rats. J. Pineal Res. 54, 381-388. doi: $10.1111 /$ jpi.12012

Ainslie, P. N., Murrell, C., Peebles, K., Swart, M., Skinner, M. A., Williams, M. J., et al. (2007). Early morning impairment in cerebral autoregulation and cerebrovascular $\mathrm{CO}_{2}$ reactivity in healthy humans: relation to endothelial function. Exp. Physiol. 92, 769-777. doi: 10.1113/expphysiol.2006.036814

Akcay, Y. D., Yalcin, A., and Sozmen, E. Y. (2005). The effect of melatonin on lipid peroxidation and nitrite/nitrate levels, and on superoxide dismutase and catalase activities in kainic acid-induced injury. Cell Mol. Biol. Lett. 10, 321-329.

Aladag, M. A., Turkoz, Y., Parlakpinar, H., Ozen, H., Egri, M., and Unal, S. C. (2009). Melatonin ameliorates cerebral vasospasm after experimental subarachnoidal haemorrhage correcting imbalance of nitric oxide levels in rats. Neurochem. Res. 34, 1935-1944. doi: 10.1007/s11064-009-9979-7

Al-Ghoul, W. M., Herman, M. D., and Dubocovich, M. L. (1998). Melatonin receptor subtype expression in human cerebellum. Neuroreport 9, 4063-4068. doi: 10.1097/00001756-199812210-00011

Arangino, S., Cagnacci, A., Angiolucci, M., Vacca, A. M., Longu, G., Volpe, A., et al. (1999). Effects of melatonin on vascular reactivity, catecholamine levels, and blood pressure in healthy men. Am. J. Cardiol. 83, 1417-1419. doi: 10.1016/ S0002-9149(99)00112-5

Armstead, W. M., Hekierski, H., Pastor, P., Yarovoi, S., Higazi, A. A., and Cines, D. B. (2018). Release of IL-6 after stroke contributes to impaired cerebral autoregulation and hippocampal neuronal necrosis through NMDA receptor activation and upregulation of ET-1 and JNK. Transl. Stroke Res. doi: 10.1007/ s12975-018-0617-z [Epub ahead of print].

Armstead, W. M., Kiessling, J. W., Bdeir, K., Kofke, W. A., and Vavilala, M. S. (2010a). Adrenomedullin prevents sex-dependent impairment of autoregulation during hypotension after piglet brain injury through inhibition of ERK MAPK upregulation. J. Neurotrauma 27, 391-402. doi: 10.1089/neu. 2009.1094

Armstead, W. M., Kiessling, J. W., Kofke, W. A., and Vavilala, M. S. (2010b). SNP improves cerebral hemodynamics during normotension but fails to prevent sex dependent impaired cerebral autoregulation during hypotension after brain injury. Brain Res. 1330, 142-150. doi: 10.1016/j.brainres.2010.03.024

Armstead, W. M., Riley, J., and Vavilala, M. S. (2016). Norepinephrine protects cerebral autoregulation and reduces hippocampal necrosis after traumatic brain injury via blockade of ERK MAPK and IL-6 in juvenile pigs. J. Neurotrauma 33, 1761-1767. doi: 10.1089/neu.2015.4290

Aubineau, P., Sercombe, R., and Seylaz, J. (1980). Parasympathomimetic influence of carbachol on local cerebral blood flow in the rabbit by a direct vasodilator action and an inhibition of the sympathetic-mediated vasoconstriction. $\mathrm{Br}$. J. Pharmacol. 68, 449-459. doi: 10.1111/j.1476-5381.1980.tb14558.x

Baerts, W., van Bel, F., Thewissen, L., Derks, J. B., and Lemmers, P. M. (2013). Tocolytic indomethacin: effects on neonatal haemodynamics and cerebral

\section{AUTHOR CONTRIBUTIONS}

Z-NG, HJ, HS, and YZ wrote the manuscript. JL and HM prepared the figures. XS and YY reviewed and edited the manuscript.

\section{FUNDING}

The authors disclosed receipt of the following financial support for the publication of this article: the National Key R\&D Program of China (2016YFC1301603, 2016YFC1301600) and the Program for JLUSTIRT (2017TD-12) to YY. This project was also supported by the Science and Technology Development Project of Jilin Province (20170520013JH) to HJ.

autoregulation in the preterm newborn. Arch. Dis. Child. Fetal Neonatal Ed. 98, F419-F423. doi: 10.1136/archdischild-2012-302532

Bailey, D. M., Evans, K. A., McEneny, J., Young, I. S., Hullin, D. A., James, P. E., et al. (2011). Exercise-induced oxidative-nitrosative stress is associated with impaired dynamic cerebral autoregulation and blood-brain barrier leakage. Exp. Physiol. 96, 1196-1207. doi: 10.1113/expphysiol.2011.060178

Bang, J., Park, Y. S., Jeong, S. M., Song, J. G., Kim, Y. K., and Hwang, G. S. (2012). Melatonin does not attenuate dynamic cardiovascular and cerebrovascular reflex responses to acute hypotension in healthy men. Korean J. Anesthesiol. 63, 245-252. doi: 10.4097/kjae.2012.63.3.245

Banki, N. M., Kopelnik, A., Dae, M. W., Miss, J., Tung, P., Lawton, M. T., et al. (2005). Acute neurocardiogenic injury after subarachnoid hemorrhage. Circulation 112, 3314-3319. doi: 10.1161/CIRCULATIONAHA.105.558239

Bayliss, W. M. (1902). On the local reactions of the arterial wall to changes of internal pressure. J. Physiol. 28, 220-231. doi: 10.1113/jphysiol.1902.sp 000911

Beker, M. C., Caglayan, A. B., Kelestemur, T., Caglayan, B., Yalcin, E., Yulug, B., et al. (2015). Effects of normobaric oxygen and melatonin on reperfusion injury: role of cerebral microcirculation. Oncotarget 6, 30604-30614. doi: 10.18632/ oncotarget. 5773

Blanco, S., Hernandez, R., Franchelli, G., Ramos-Alvarez, M. M., and Peinado, M. A. (2017). Melatonin influences NO/NOS pathway and reduces oxidative and nitrosative stress in a model of hypoxic-ischemic brain damage. Nitric Oxide 62, 32-43. doi: 10.1016/j.niox.2016.12.001

Boussard, M. F., Truche, S., Rousseau-Rojas, A., Briss, S., Descamps, S., Droual, M., et al. (2006). New ligands at the melatonin binding site MT(3). Eur. J. Med. Chem. 41, 306-320. doi: 10.1016/j.ejmech.2005.12.002

Bruls, E., Crasson, M., and Legros, J. J. (2000). [Melatonin. I. Physiology of its secretion]. Rev. Med. Liege 55, 785-792.

Budohoski, K. P., Czosnyka, M., Kirkpatrick, P. J., Reinhard, M., Varsos, G. V., Kasprowicz, M., et al. (2015). Bilateral failure of cerebral autoregulation is related to unfavorable outcome after subarachnoid hemorrhage. Neurocrit. Care 22, 65-73. doi: 10.1007/s12028-014-0032-6

Budohoski, K. P., Czosnyka, M., Smielewski, P., Kasprowicz, M., Helmy, A., Bulters, D., et al. (2012). Impairment of cerebral autoregulation predicts delayed cerebral ischemia after subarachnoid hemorrhage: a prospective observational study. Stroke 43, 3230-3237. doi: 10.1161/STROKEAHA.112.669788

Budohoski, K. P., Czosnyka, M., Smielewski, P., Varsos, G. V., Kasprowicz, M., Brady, K. M., et al. (2013). Cerebral autoregulation after subarachnoid hemorrhage: comparison of three methods. J. Cereb. Blood Flow Metab. 33, 449-456. doi: 10.1038/jcbfm.2012.189

Budohoski, K. P., Czosnyka, M., Smielewski, P., Varsos, G. V., Kasprowicz, M., Brady, K. M., et al. (2016). Monitoring cerebral autoregulation after subarachnoid hemorrhage. Acta Neurochir. Suppl. 122, 199-203. doi: 10.1007/ 978-3-319-22533-3_40

Busija, D. W. (1985). Sustained cerebral vasoconstriction during bilateral sympathetic stimulation in anesthetized rabbits. Brain Res. 345, 341-344. doi: 10.1016/0006-8993(85)91013-3 
Cagnacci, A., Arangino, S., Angiolucci, M., Maschio, E., and Melis, G. B. (1998). Influences of melatonin administration on the circulation of women. Am. J. Physiol. 274(2 Pt 2), R335-338. doi: 10.1152/ajpregu.1998.274.2.R335

Calviere, L., Nasr, N., Arnaud, C., Czosnyka, M., Viguier, A., Tissot, B., et al. (2015). Prediction of delayed cerebral ischemia after subarachnoid hemorrhage using cerebral blood flow velocities and cerebral autoregulation assessment. Neurocrit. Care 23, 253-258. doi: 10.1007/s12028-015-0125-x

Carrascal, L., Nunez-Abades, P., Ayala, A., and Cano, M. (2018). Role of melatonin in the inflammatory process and its therapeutic potential. Curr. Pharm. Des. 24, 1563-1588. doi: 10.2174/1381612824666180426112832

Carretero, M., Escames, G., Lopez, L. C., Venegas, C., Dayoub, J. C., Garcia, L., et al. (2009). Long-term melatonin administration protects brain mitochondria from aging. J. Pineal Res. 47, 192-200. doi: 10.1111/j.1600-079X.2009.00700.x

Carvi y Nievas, M., Toktamis, S., Hollerhage, H. G., and Haas, E. (2005). Hyperacute measurement of brain-tissue oxygen, carbon dioxide, $\mathrm{pH}$, and intracranial pressure before, during, and after cerebral angiography in patients with aneurysmatic subarachnoid hemorrhage in poor condition. Surg. Neurol. 64, 362-367; discussion 367. doi: 10.1016/j.surneu.2005.02.008

Chen, J., Chen, G., Li, J., Qian, C., Mo, H., Gu, C., et al. (2014a). Melatonin attenuates inflammatory response-induced brain edema in early brain injury following a subarachnoid hemorrhage: a possible role for the regulation of pro-inflammatory cytokines. J. Pineal Res. 57, 340-347. doi: 10.1111/jpi.12173

Chen, J., Liu, J., Xu, W. H., Xu, R., Hou, B., Cui, L. Y., et al. (2014b). Impaired dynamic cerebral autoregulation and cerebrovascular reactivity in middle cerebral artery stenosis. PLoS One 9:e88232. doi: 10.1371/journal.pone.0088232

Chen, J., Wang, L., Wu, C., Hu, Q., Gu, C., Yan, F., et al. (2014c). Melatoninenhanced autophagy protects against neural apoptosis via a mitochondrial pathway in early brain injury following a subarachnoid hemorrhage. J. Pineal Res. 56, 12-19. doi: 10.1111/jpi.12086

Chen, J., Qian, C., Duan, H., Cao, S., Yu, X., Li, J., et al. (2015). Melatonin attenuates neurogenic pulmonary edema via the regulation of inflammation and apoptosis after subarachnoid hemorrhage in rats. J. Pineal Res. 59, 469-477. doi: $10.1111 /$ jpi.12278

Chock, V. Y., Ramamoorthy, C., and Van Meurs, K. P. (2012). Cerebral autoregulation in neonates with a hemodynamically significant patent ductus arteriosus. J. Pediatr. 160, 936-942. doi: 10.1016/j.jpeds.2011. 11.054

Choi, J. M., Kim, C. D., and Hong, K. W. (2001). Involvement of NADH/NADPH oxidase-derived superoxide in experimental vasospasm induced by periarterial blood in rat femoral artery. Life Sci. 69, 1753-1763. doi: 10.1016/S00243205(01)01273-5

Cosentino, F., Sill, J. C., and Katusic, Z. S. (1994). Role of superoxide anions in the mediation of endothelium-dependent contractions. Hypertension 23, 229-235. doi: 10.1161/01.HYP.23.2.229

Cristofanon, S., Morceau, F., Scovassi, A. I., Dicato, M., Ghibelli, L., and Diederich, M. (2009). Oxidative, multistep activation of the noncanonical NF-kappaB pathway via disulfide Bcl-3/p50 complex. FASEB J. 23, 45-57. doi: 10.1096/fj.07-104109

de Azevedo, D. S., Salinet, A. S. M., de Lima Oliveira, M., Teixeira, M. J., Bor-SengShu, E., and de Carvalho Nogueira, R. (2017). Cerebral hemodynamics in sepsis assessed by transcranial Doppler: a systematic review and meta-analysis. J. Clin. Monit. Comput. 31, 1123-1132. doi: 10.1007/s10877-016-9945-2

Deng, W., Kandhi, S., Zhang, B., Huang, A., Koller, A., and Sun, D. (2018). Extravascular blood augments myogenic constriction of cerebral arterioles: implications for hemorrhage-induced vasospasm. J. Am. Heart Assoc. 7:e008623. doi: 10.1161/JAHA.118.008623

Dilraj, A., Botha, J. H., Rambiritch, V., Miller, R., and van Dellen, J. R. (1992). Levels of catecholamine in plasma and cerebrospinal fluid in aneurysmal subarachnoid hemorrhage. Neurosurgery 31, 42-50; discussion 50-41.

Dong, Y., Fan, C., Hu, W., Jiang, S., Ma, Z., Yan, X., et al. (2016). Melatonin attenuated early brain injury induced by subarachnoid hemorrhage via regulating NLRP3 inflammasome and apoptosis signaling. J. Pineal Res. 60, 253-262. doi: 10.1111/jpi.12300

Doolen, S., Krause, D. N., Dubocovich, M. L., and Duckles, S. P. (1998). Melatonin mediates two distinct responses in vascular smooth muscle. Eur. J. Pharmacol. 345, 67-69. doi: 10.1016/S0014-2999(98)00064-8

Edvinsson, L., Aubineau, P., Owman, C., Sercombe, R., and Seylaz, J. (1975). Sympathetic innervation of cerebral arteries: prejunctional supersensitivity to norepinephrine after sympathectomy or cocaine treatment. Stroke 6, 525-530. doi: 10.1161/01.STR.6.5.525

Ekmekcioglu, C. (2006). Melatonin receptors in humans: biological role and clinical relevance. Biomed. Pharmacother. 60, 97-108. doi: 10.1016/j.biopha. 2006.01 .002

Emet, M., Ozcan, H., Ozel, L., Yayla, M., Halici, Z., and Hacimuftuoglu, A. (2016). A review of melatonin, its receptors and drugs. Eurasian J. Med. 48, 135-141. doi: 10.5152/eurasianjmed.2015.0267

Ersahin, M., Toklu, H. Z., Cetinel, S., Yuksel, M., Erzik, C., Berkman, M. Z., et al. (2010). Alpha lipoic acid alleviates oxidative stress and preserves blood brain permeability in rats with subarachnoid hemorrhage. Neurochem. Res. 35, 418-428. doi: 10.1007/s11064-009-0072-Z

Fang, Q., Chen, G., Zhu, W., Dong, W., and Wang, Z. (2009). Influence of melatonin on cerebrovascular proinflammatory mediators expression and oxidative stress following subarachnoid hemorrhage in rabbits. Mediators Inflamm. 2009:426346. doi: 10.1155/2009/426346

Faraci, F. M. (2006). Reactive oxygen species: influence on cerebral vascular tone. J. Appl. Physiol. 100, 739-743. doi: 10.1152/japplphysiol.01044.2005

Feng, D., Wang, B., Wang, L., Abraham, N., Tao, K., Huang, L., et al. (2017). Preischemia melatonin treatment alleviated acute neuronal injury after ischemic stroke by inhibiting endoplasmic reticulum stress-dependent autophagy via PERK and IRE1 signalings. J. Pineal Res. 62:e12395. doi: 10.1111/jpi. 12395

Fu, J., Xia, X., Liu, Z., Wang, Y., Shi, Q., Song, X., et al. (2017). The acute exposure of tetrachloro-p-benzoquinone (a.k.a. chloranil) triggers inflammation and neurological dysfunction via Toll-like receptor 4 signaling: the protective role of melatonin preconditioning. Toxicology 381, 39-50. doi: 10.1016/j.tox.2017. 02.015

Gaasch, M., Schiefecker, A. J., Kofler, M., Beer, R., Rass, V., Pfausler, B., et al. (2018). Cerebral autoregulation in the prediction of delayed cerebral ischemia and clinical outcome in poor-grade aneurysmal subarachnoid hemorrhage patients. Crit. Care Med. 46, 774-780. doi: 10.1097/CCM.0000000000003016

Garcia, J. J., Lopez-Pingarron, L., Almeida-Souza, P., Tres, A., Escudero, P., GarciaGil, F. A., et al. (2014). Protective effects of melatonin in reducing oxidative stress and in preserving the fluidity of biological membranes: a review. J. Pineal Res. 56, 225-237. doi: 10.1111/jpi.12128

Girouard, H., Denault, C., Chulak, C., and de Champlain, J. (2004). Treatment by $\mathrm{n}$-acetylcysteine and melatonin increases cardiac baroreflex and improves antioxidant reserve. Am. J. Hypertens. 17, 947-954. doi: 10.1016/j.amjhyper. 2004.06.009

Grad, A., Kiauta, T., and Osredkar, J. (1991). Effect of elevated plasma norepinephrine on electrocardiographic changes in subarachnoid hemorrhage. Stroke 22, 746-749. doi: 10.1161/01.STR.22.6.746

Guerrero, J. M., Reiter, R. J., Ortiz, G. G., Pablos, M. I., Sewerynek, E., and Chuang, J. I. (1997). Melatonin prevents increases in neural nitric oxide and cyclic GMP production after transient brain ischemia and reperfusion in the Mongolian gerbil (Meriones unguiculatus). J. Pineal Res. 23, 24-31. doi: 10.1111/j.1600079X.1997.tb00331.X

Guo, Z. N., Liu, J., Xing, Y., Yan, S., Lv, C., Jin, H., et al. (2014). Dynamic cerebral autoregulation is heterogeneous in different subtypes of acute ischemic stroke. PLoS One 9:e93213. doi: 10.1371/journal.pone.0093213

Guo, Z. N., Shao, A., Tong, L. S., Sun, W., Liu, J., and Yang, Y. (2016). The role of nitric oxide and sympathetic control in cerebral autoregulation in the setting of subarachnoid hemorrhage and traumatic brain injury. Mol. Neurobiol. 53, 3606-3615. doi: 10.1007/s12035-015-9308-x

Hamner, J. W., and Tan, C. O. (2014). Relative contributions of sympathetic, cholinergic, and myogenic mechanisms to cerebral autoregulation. Stroke 45, 1771-1777. doi: 10.1161/STROKEAHA.114.005293

Hamner, J. W., Tan, C. O., Lee, K., Cohen, M. A., and Taylor, J. A. (2010). Sympathetic control of the cerebral vasculature in humans. Stroke 41, 102-109. doi: 10.1161/STROKEAHA.109.557132

Hardeland, R., Backhaus, C., Fadavi, A., and Hess, M. (2007). N(1)-acetyl-5methoxykynuramine contrasts with other tryptophan metabolites by a peculiar type of NO scavenging: cyclization to a cinnolinone prevents formation of unstable nitrosamines. J. Pineal Res. 43, 104-105. doi: 10.1111/j.1600-079X. 2007.00431.x

Herrera, E. A., Macchiavello, R., Montt, C., Ebensperger, G., Diaz, M., Ramirez, S., et al. (2014). Melatonin improves cerebrovascular function and decreases 
oxidative stress in chronically hypoxic lambs. J. Pineal Res. 57, 33-42. doi: 10.1111/jpi.12141

Jahromi, B. S., Aihara, Y., Ai, J., Zhang, Z. D., Nikitina, E., and Macdonald, R. L. (2008). Voltage-gated $\mathrm{K}+$ channel dysfunction in myocytes from a dog model of subarachnoid hemorrhage. J. Cereb. Blood Flow Metab. 28, 797-811. doi: $10.1038 /$ sj.jcbfm. 9600577

Jumnongprakhon, P., Govitrapong, P., Tocharus, C., and Tocharus, J. (2016). Melatonin promotes blood-brain barrier integrity in methamphetamineinduced inflammation in primary rat brain microvascular endothelial cells. Brain Res. 1646, 182-192. doi: 10.1016/j.brainres.2016.05.049

Kajita, Y., Takayasu, M., Dietrich, H. H., and Dacey, R. G. (1998). Possible role of nitric oxide in autoregulatory response in rat intracerebral arterioles. Neurosurgery 42, 834-841; discussion 841-832. doi: 10.1097/00006123199804000-00087

Kang, Y. S., Kang, Y. G., Park, H. J., Wee, H. J., Jang, H. O., Bae, M. K., et al. (2013). Melatonin inhibits visfatin-induced inducible nitric oxide synthase expression and nitric oxide production in macrophages. J. Pineal Res. 55, 294-303. doi: $10.1111 /$ jpi.12072

K-Laflamme, A., Wu, L., Foucart, S., and de Champlain, J. (1998). Impaired basal sympathetic tone and alpha1-adrenergic responsiveness in association with the hypotensive effect of melatonin in spontaneously hypertensive rats. Am. J. Hypertens. 11, 219-229. doi: 10.1016/S0895-7061(97)00401-9

Lang, E. W., Diehl, R. R., and Mehdorn, H. M. (2001). Cerebral autoregulation testing after aneurysmal subarachnoid hemorrhage: the phase relationship between arterial blood pressure and cerebral blood flow velocity. Crit. Care Med. 29, 158-163. doi: 10.1097/00003246-200101000-00031

Lapi, D., Vagnani, S., Cardaci, E., Paterni, M., and Colantuoni, A. (2011). Rat pial microvascular responses to melatonin during bilateral common carotid artery occlusion and reperfusion. J. Pineal Res. 51, 136-144. doi: 10.1111/j.1600-079X. 2011.00870.x

Lee, W. S., Kwon, Y. J., Yu, S. S., Rhim, B. Y., and Hong, K. W. (1993). Disturbances in autoregulatory responses of rat pial arteries by sulfonylureas. Life Sci. 52, 1527-1534. doi: 10.1016/0024-3205(93)90053-6

Lekic, T., Hartman, R., Rojas, H., Manaenko, A., Chen, W., Ayer, R., et al. (2010). Protective effect of melatonin upon neuropathology, striatal function, and memory ability after intracerebral hemorrhage in rats. J. Neurotrauma 27, 627-637. doi: 10.1089/neu.2009.1163

Lew, M. J., and Flanders, S. (1999). Mechanisms of melatonin-induced vasoconstriction in the rat tail artery: a paradigm of weak vasoconstriction. $\mathrm{Br}$. J. Pharmacol. 126, 1408-1418. doi: 10.1038/sj.bjp.0702435

Li, J., Chen, J., Mo, H., Qian, C., Yan, F., Gu, C., et al. (2016). Minocycline protects against NLRP3 inflammasome-induced inflammation and P53-associated apoptosis in early brain injury after subarachnoid hemorrhage. Mol. Neurobiol. 53, 2668-2678. doi: 10.1007/s12035-015-9318-8

Li, Z. Q., Liang, G. B., Xue, Y. X., and Liu, Y. H. (2009). Effects of combination treatment of dexamethasone and melatonin on brain injury in intracerebral hemorrhage model in rats. Brain Res. 1264, 98-103. doi: 10.1016/j.brainres. 2009.01.055

Lidington, D., Kroetsch, J. T., and Bolz, S. S. (2018). Cerebral artery myogenic reactivity: the next frontier in developing effective interventions for subarachnoid hemorrhage. J. Cereb. Blood Flow Metab. 38, 17-37. doi: 10.1177/ 0271678X17742548

Liu, L., Fujimoto, M., Kawakita, F., Nakano, F., Imanaka-Yoshida, K., Yoshida, T., et al. (2016). Anti-vascular endothelial growth factor treatment suppresses early brain injury after subarachnoid hemorrhage in mice. Mol. Neurobiol. 53, 4529-4538. doi: 10.1007/s12035-015-9386-9

Liu, X., Czosnyka, M., Donnelly, J., Budohoski, K. P., Varsos, G. V., Nasr, N., et al. (2015). Comparison of frequency and time domain methods of assessment of cerebral autoregulation in traumatic brain injury. J. Cereb. Blood Flow Metab. 35, 248-256. doi: 10.1038/jcbfm.2014.192

Lopez, A., Garcia, J. A., Escames, G., Venegas, C., Ortiz, F., Lopez, L. C., et al. (2009). Melatonin protects the mitochondria from oxidative damage reducing oxygen consumption, membrane potential, and superoxide anion production. J. Pineal Res. 46, 188-198. doi: 10.1111/j.1600-079X.2008.00647.x

Lopez, L. C., Escames, G., Tapias, V., Utrilla, P., Leon, J., and Acuna-Castroviejo, D. (2006). Identification of an inducible nitric oxide synthase in diaphragm mitochondria from septic mice: its relation with mitochondrial dysfunction and prevention by melatonin. Int. J. Biochem. Cell Biol. 38, 267-278. doi: 10.1016/j. biocel.2005.09.008

Ma, H., Guo, Z. N., Liu, J., Xing, Y., Zhao, R., and Yang, Y. (2016). Temporal course of dynamic cerebral autoregulation in patients with intracerebral hemorrhage. Stroke 47, 674-681. doi: 10.1161/STROKEAHA.115.011453

Manchester, L. C., Coto-Montes, A., Boga, J. A., Andersen, L. P., Zhou, Z., Galano, A., et al. (2015). Melatonin: an ancient molecule that makes oxygen metabolically tolerable. J. Pineal Res. 59, 403-419. doi: 10.1111/jpi.12267

Masana, M. I., Doolen, S., Ersahin, C., Al-Ghoul, W. M., Duckles, S. P., Dubocovich, M. L., et al. (2002). MT(2) melatonin receptors are present and functional in rat caudal artery. J. Pharmacol. Exp. Ther. 302, 1295-1302. doi: 10.1124/jpet.302.3.1295

Mauriz, J. L., Collado, P. S., Veneroso, C., Reiter, R. J., and Gonzalez-Gallego, J. (2013). A review of the molecular aspects of melatonin's anti-inflammatory actions: recent insights and new perspectives. J. Pineal Res. 54, 1-14. doi: 10. 1111/j.1600-079X.2012.01014.x

Moussouttas, M., Huynh, T. T., Khoury, J., Lai, E. W., Dombrowski, K., Pello, S., et al. (2012a). Cerebrospinal fluid catecholamine levels as predictors of outcome in subarachnoid hemorrhage. Cerebrovasc. Dis. 33, 173-181. doi: 10.1159/ 000334660

Moussouttas, M., Lai, E. W., Khoury, J., Huynh, T. T., Dombrowski, K., and Pacak, K. (2012b). Determinants of central sympathetic activation in spontaneous primary subarachnoid hemorrhage. Neurocrit. Care 16, 381-388. doi: 10.1007/s12028-012-9673-5

Moussouttas, M., Lai, E. W., Huynh, T. T., James, J., Stocks-Dietz, C., Dombrowski, K., et al. (2014). Association between acute sympathetic response, early onset vasospasm, and delayed vasospasm following spontaneous subarachnoid hemorrhage. J. Clin. Neurosci. 21, 256-262. doi: 10.1016/j.jocn. 2013.03.036

Muller, M. D., Sauder, C. L., and Ray, C. A. (2013). Melatonin attenuates the skin sympathetic nerve response to mental stress. Am. J. Physiol. Heart Circ. Physiol. 305, H1382-H1386. doi: 10.1152/ajpheart.00470.2013

Naredi, S., Lambert, G., Eden, E., Zall, S., Runnerstam, M., Rydenhag, B., et al. (2000). Increased sympathetic nervous activity in patients with nontraumatic subarachnoid hemorrhage. Stroke 31, 901-906. doi: 10.1161/01.STR.31.4.901

Nelson, M. T., and Quayle, J. M. (1995). Physiological roles and properties of potassium channels in arterial smooth muscle. Am. J. Physiol. 268(4 Pt 1), C799-C822. doi: 10.1152/ajpcell.1995.268.4.C799

Olmez, E., and Kurcer, Z. (2003). Melatonin attenuates alpha-adrenergic-induced contractions by increasing the release of vasoactive intestinal peptide in isolated rat penile bulb. Urol. Res. 31, 276-279. doi: 10.1007/s00240-003-0327-0

Otite, F., Mink, S., Tan, C. O., Puri, A., Zamani, A. A., Mehregan, A., et al. (2014). Impaired cerebral autoregulation is associated with vasospasm and delayed cerebral ischemia in subarachnoid hemorrhage. Stroke 45, 677-682. doi: 10.1161/STROKEAHA.113.002630

Pandi-Perumal, S. R., Trakht, I., Srinivasan, V., Spence, D. W., Maestroni, G. J., Zisapel, N., et al. (2008). Physiological effects of melatonin: role of melatonin receptors and signal transduction pathways. Prog. Neurobiol. 85, 335-353. doi: 10.1016/j.pneurobio.2008.04.001

Paulson, O. B., Strandgaard, S., and Edvinsson, L. (1990). Cerebral autoregulation. Cerebrovasc. Brain Metab. Rev. 2, 161-192.

Pawlowska, E., Szczepanska, J., Wisniewski, K., Tokarz, P., Jaskolski, D. J., and Blasiak, J. (2018). NF-kappaB-mediated inflammation in the pathogenesis of intracranial aneurysm and subarachnoid hemorrhage. Does autophagy play a role? Int. J. Mol. Sci. 19:E1245. doi: 10.3390/ijms19041245

Pazar, A., Kolgazi, M., Memisoglu, A., Bahadir, E., Sirvanci, S., Yaman, A., et al. (2016). The neuroprotective and anti-apoptotic effects of melatonin on hemolytic hyperbilirubinemia-induced oxidative brain damage. J. Pineal Res. 60, 74-83. doi: 10.1111/jpi.12292

Pei, Z., Fung, P. C., and Cheung, R. T. (2003). Melatonin reduces nitric oxide level during ischemia but not blood-brain barrier breakdown during reperfusion in a rat middle cerebral artery occlusion stroke model. J. Pineal Res. 34, 110-118. doi: 10.1034/j.1600-079X.2003.00014.X

Preckel, M. P., Leftheriotis, G., Ferber, C., Degoute, C. S., Banssillon, V., and Saumet, J. L. (1996). Effect of nitric oxide blockade on the lower limit of the cortical cerebral autoregulation in pentobarbital-anaesthetized rats. Int. J. Microcirc. Clin. Exp. 16, 277-283. doi: 10.1159/000179186 
Pries, A. R., Secomb, T. W., and Gaehtgens, P. (2000). The endothelial surface layer. Pflugers Arch. 440, 653-666. doi: 10.1007/s004240000307

Qin, W., Lu, W., Li, H., Yuan, X., Li, B., Zhang, Q., et al. (2012). Melatonin inhibits IL1beta-induced MMP9 expression and activity in human umbilical vein endothelial cells by suppressing NF-kappaB activation. J. Endocrinol. 214, 145-153. doi: 10.1530/JOE-12-0147

Radogna, F., Diederich, M., and Ghibelli, L. (2010). Melatonin: a pleiotropic molecule regulating inflammation. Biochem. Pharmacol. 80, 1844-1852. doi: 10.1016/j.bcp.2010.07.041

Ray, C. A. (2003). Melatonin attenuates the sympathetic nerve responses to orthostatic stress in humans. J. Physiol. 551(Pt 3), 1043-1048. doi: 10.1113/ jphysiol.2003.043182

Régrigny, O., Delagrange, P., Scalbert, E., Lartaud-Idjouadiene, I., Atkinson, J., and Chillon, J. M. (1999). Effects of melatonin on rat pial arteriolar diameter in vivo. Br. J. Pharmacol. 127, 1666-1670. doi: 10.1038/sj.bjp.0702714

Reiter, R. J., Tan, D. X., Qi, W., Manchester, L. C., Karbownik, M., and Calvo, J. R. (2000). Pharmacology and physiology of melatonin in the reduction of oxidative stress in vivo. Biol. Signals Recept. 9, 160-171. doi: 10.1159/0000 14636

Reppert, S. M., Godson, C., Mahle, C. D., Weaver, D. R., Slaugenhaupt, S. A., and Gusella, J. F. (1995). Molecular characterization of a second melatonin receptor expressed in human retina and brain: the Mellb melatonin receptor. Proc. Natl. Acad. Sci. U.S.A. 92, 8734-8738. doi: 10.1073/pnas.92.19.8734

Rodella, L. F., Favero, G., Foglio, E., Rossini, C., Castrezzati, S., Lonati, C., et al. (2013). Vascular endothelial cells and dysfunctions: role of melatonin. Front. Biosci. 5, 119-129.

Rosenblum, W. I. (1983). Effects of free radical generation on mouse pial arterioles: probable role of hydroxyl radicals. Am. J. Physiol. 245, H139-H142. doi: 10. 1152/ajpheart.1983.245.1.H139

Sabri, M., Ai, J., Knight, B., Tariq, A., Jeon, H., Shang, X., et al. (2011). Uncoupling of endothelial nitric oxide synthase after experimental subarachnoid hemorrhage. J. Cereb. Blood Flow Metab. 31, 190-199. doi: $10.1038 / \mathrm{jcbfm} .2010 .76$

Sadoshima, S., Yoshida, F., Ibayashi, S., Shiokawa, O., and Fujishima, M. (1985). Upper limit of cerebral autoregulation during development of hypertension in spontaneously hypertensive rats-effect of sympathetic denervation. Stroke 16, 477-481. doi: 10.1161/01.STR.16.3.477

Santos, G. A., Petersen, N., Zamani, A. A., Du, R., LaRose, S., Monk, A., et al. (2016). Pathophysiologic differences in cerebral autoregulation after subarachnoid hemorrhage. Neurology 86, 1950-1956. doi: 10.1212/WNL. 0000000000002696

Savaskan, E., Ayoub, M. A., Ravid, R., Angeloni, D., Fraschini, F., Meier, F., et al. (2005). Reduced hippocampal MT2 melatonin receptor expression in Alzheimer's disease. J. Pineal Res. 38, 10-16. doi: 10.1111/j.1600-079X.2004. 00169.x

Savaskan, E., Olivieri, G., Meier, F., Brydon, L., Jockers, R., Ravid, R., et al. (2002). Increased melatonin 1a-receptor immunoreactivity in the hippocampus of Alzheimer's disease patients. J. Pineal Res. 32, 59-62. doi: 10.1034/j.1600-079x. 2002.00841.x

Scharbrodt, W., Abdallah, Y., Kasseckert, S. A., Gligorievski, D., Piper, H. M., Boker, D. K., et al. (2009). Cytosolic Ca2 ${ }^{+}$oscillations in human cerebrovascular endothelial cells after subarachnoid hemorrhage. J. Cereb. Blood Flow Metab. 29, 57-65. doi: $10.1038 / \mathrm{jcbfm} .2008 .87$

Shao, A., Wu, H., Hong, Y., Tu, S., Sun, X., Wu, Q., et al. (2016). Hydrogenrich saline attenuated subarachnoid hemorrhage-induced early brain injury in rats by suppressing inflammatory response: possible involvement of NFkappaB pathway and NLRP3 inflammasome. Mol. Neurobiol. 53, 3462-3476. doi: 10.1007/s12035-015-9242-y

Shekhar, S., Liu, R., Travis, O. K., Roman, R. J., and Fan, F. (2017). Cerebral autoregulation in hypertension and ischemic stroke: a mini review. J. Pharm. Sci. Exp. Pharmacol. 2017, 21-27.

Shin, H. K., and Hong, K. W. (2004). Importance of calcitonin gene-related peptide, adenosine and reactive oxygen species in cerebral autoregulation under normal and diseased conditions. Clin. Exp. Pharmacol. Physiol. 31, 1-7. doi: 10.1111/j. 1440-1681.2004.03943.x

Shin, H. K., Lee, J. H., Kim, K. Y., Kim, C. D., Lee, W. S., Rhim, B. Y., et al. (2002). Impairment of autoregulatory vasodilation by $\mathrm{NAD}(\mathrm{P}) \mathrm{H}$ oxidase-dependent superoxide generation during acute stage of subarachnoid hemorrhage in rat pial artery. J. Cereb. Blood Flow Metab. 22, 869-877. doi: 10.1097/00004647200207000-00012

Simko, F., and Paulis, L. (2007). Melatonin as a potential antihypertensive treatment. J. Pineal Res. 42, 319-322. doi: 10.1111/j.1600-079X.2007.00436.x

Sinha, B., Wu, Q., Li, W., Tu, Y., Sirianni, A. C., Chen, Y., et al. (2018). Protection of melatonin in experimental models of newborn hypoxic-ischemic brain injury through MT1 receptor. J. Pineal Res. 64:e12443 doi: 10.1111/jpi.12443

Sobey, C. G., and Faraci, F. M. (1998). Subarachnoid haemorrhage: what happens to the cerebral arteries? Clin. Exp. Pharmacol. Physiol. 25, 867-876. doi: 10.1111/j. 1440-1681.1998.tb02337.x

Soehle, M., Czosnyka, M., Pickard, J. D., and Kirkpatrick, P. J. (2004). Continuous assessment of cerebral autoregulation in subarachnoid hemorrhage. Anesth. Analg. 98, 1133-1139, Table of Contents. doi: 10.1213/01.ANE.0000111101. 41190.99

Strandgaard, S., and Paulson, O. B. (1984). Cerebral autoregulation. Stroke 15, 413-416. doi: 10.1161/01.STR.15.3.413

Szatmari, S., Vegh, T., Csomos, A., Hallay, J., Takacs, I., Molnar, C., et al. (2010). Impaired cerebrovascular reactivity in sepsis-associated encephalopathy studied by acetazolamide test. Crit. Care 14:R50. doi: 10.1186/cc8939

Tan, D., Manchester, L. C., Reiter, R. J., Qi, W., Hanes, M. A., and Farley, N. J. (1999). High physiological levels of melatonin in the bile of mammals. Life Sci. 65, 2523-2529. doi: 10.1016/S0024-3205(99)00519-6

Tan, D. X., Manchester, L. C., Reiter, R. J., Qi, W. B., Zhang, M., Weintraub, S. T., et al. (1999). Identification of highly elevated levels of melatonin in bone marrow: its origin and significance. Biochim. Biophys. Acta 1472, 206-214. doi: 10.1016/S0304-4165(99)00125-7

Tan, D. X., Manchester, L. C., Terron, M. P., Flores, L. J., and Reiter, R. J. (2007). One molecule, many derivatives: a never-ending interaction of melatonin with reactive oxygen and nitrogen species? J. Pineal Res. 42, 28-42. doi: 10.1111/j. 1600-079X.2006.00407.x

Tan, D. X., Reiter, R. J., Manchester, L. C., Yan, M. T., El-Sawi, M., Sainz, R. M., et al. (2002). Chemical and physical properties and potential mechanisms: melatonin as a broad spectrum antioxidant and free radical scavenger. Curr. Top. Med. Chem 2, 181-197. doi: 10.2174/1568026023394443

Taniguti, E. H., Ferreira, Y. S., Stupp, I. J. V., Fraga-Junior, E. B., Mendonca, C. B., Rossi, F. L., et al. (2018). Neuroprotective effect of melatonin against lipopolysaccharide-induced depressive-like behavior in mice. Physiol. Behav. 188, 270-275. doi: 10.1016/j.physbeh.2018.02.034

Thomas, L., Purvis, C. C., Drew, J. E., Abramovich, D. R., and Williams, L. M. (2002). Melatonin receptors in human fetal brain: 2-[(125)I]iodomelatonin binding and MT1 gene expression. J. Pineal Res. 33, 218-224. doi: 10.1034/j. 1600-079X.2002.02921.x

Tjong, Y. W., Li, M. F., Hung, M. W., and Fung, M. L. (2008). Melatonin ameliorates hippocampal nitric oxide production and large conductance calcium-activated potassium channel activity in chronic intermittent hypoxia. J. Pineal Res. 44, 234-243. doi: 10.1111/j.1600-079X.2007.00515.x

Tseng, M. Y., Czosnyka, M., Richards, H., Pickard, J. D., and Kirkpatrick, P. J. (2005). Effects of acute treatment with pravastatin on cerebral vasospasm, autoregulation, and delayed ischemic deficits after aneurysmal subarachnoid hemorrhage: a phase II randomized placebo-controlled trial. Stroke 36, 1627-1632. doi: 10.1161/01.STR.0000176743.67564.5d

Tseng, M. Y., Czosnyka, M., Richards, H., Pickard, J. D., and Kirkpatrick, P. J. (2006). Effects of acute treatment with statins on cerebral autoregulation in patients after aneurysmal subarachnoid hemorrhage. Neurosurg. Focus 21:E10. doi: $10.3171 /$ foc. 2006.21.3.10

Tunstall, R. R., Shukla, P., Grazul-Bilska, A., Sun, C., and O'Rourke, S. T. (2011). MT2 receptors mediate the inhibitory effects of melatonin on nitric oxideinduced relaxation of porcine isolated coronary arteries. J. Pharmacol. Exp. Ther. 336, 127-133. doi: 10.1124/jpet.110.174482

Vavilala, M. S., Lee, L. A., and Lam, A. M. (2003). The lower limit of cerebral autoregulation in children during sevoflurane anesthesia. J. Neurosurg. Anesthesiol. 15, 307-312. doi: 10.1097/00008506-200310000-00003

Venkataraman, P., Selvakumar, K., Krishnamoorthy, G., Muthusami, S., Rameshkumar, R., Prakash, S., et al. (2010). Effect of melatonin on PCB (Aroclor 1254) induced neuronal damage and changes in $\mathrm{Cu} / \mathrm{Zn}$ superoxide dismutase and glutathione peroxidase- 4 mRNA expression in cerebral cortex, cerebellum and hippocampus of adult rats. Neurosci. Res. 66, 189-197. doi: 10.1016/j.neures.2009.10.015 
Viswanathan, M., Hissa, R., and George, J. C. (1986). Suppression of sympathetic nervous system by short photoperiod and melatonin in the Syrian hamster. Life Sci. 38, 73-79. doi: 10.1016/0024-3205(86)90277-8

Wakatsuki, A., Okatani, Y., Ikenoue, N., Shinohara, K., Watanabe, K., and Fukaya, T. (2001). Melatonin protects against oxidized low-density lipoproteininduced inhibition of nitric oxide production in human umbilical artery. J. Pineal Res. 31, 281-288. doi: 10.1034/j.1600-079X.2001.310313.x

Wang, Z., Ma, C., Meng, C. J., Zhu, G. Q., Sun, X. B., Huo, L., et al. (2012). Melatonin activates the Nrf2-ARE pathway when it protects against early brain injury in a subarachnoid hemorrhage model. J. Pineal Res. 53, 129-137. doi: 10.1111/j.1600-079X.2012.00978.x

Wang, Z., Wu, L., You, W., Ji, C., and Chen, G. (2013). Melatonin alleviates secondary brain damage and neurobehavioral dysfunction after experimental subarachnoid hemorrhage: possible involvement of TLR4mediated inflammatory pathway. J. Pineal Res. 55, 399-408. doi: 10.1111/jpi. 12087

Wang, Z., Zhou, F., Dou, Y., Tian, X., Liu, C., Li, H., et al. (2018). Melatonin alleviates intracerebral hemorrhage-induced secondary brain injury in rats via suppressing apoptosis, inflammation, oxidative stress, dna damage, and mitochondria injury. Transl. Stroke Res. 9, 74-91. doi: 10.1007/s12975-0170559-x

Weaver, D. R., and Reppert, S. M. (1996). The Mella melatonin receptor gene is expressed in human suprachiasmatic nuclei. Neuroreport 8, 109-112. doi: 10.1097/00001756-199612200-00022

Weekley, L. B. (1991). Melatonin-induced relaxation of rat aorta: interaction with adrenergic agonists. J. Pineal Res. 11, 28-34. doi: 10.1111/j.1600-079X.1991. tb00823.x

Wei, E. P., Kontos, H. A., and Beckman, J. S. (1996). Mechanisms of cerebral vasodilation by superoxide, hydrogen peroxide, and peroxynitrite. Am. J. Physiol. 271(3 Pt 2), H1262-H1266. doi: 10.1152/ajpheart.1996.271.3.H1262

White, R. P., Vallance, P., and Markus, H. S. (2000). Effect of inhibition of nitric oxide synthase on dynamic cerebral autoregulation in humans. Clin. Sci. 99, 555-560. doi: 10.1042/cs0990555

Xu, S., Pi, H., Zhang, L., Zhang, N., Li, Y., Zhang, H., et al. (2016). Melatonin prevents abnormal mitochondrial dynamics resulting from the neurotoxicity of cadmium by blocking calcium-dependent translocation of Drp1 to the mitochondria. J. Pineal Res. 60, 291-302. doi: 10.1111/jpi.12310

Yagi, K., Lidington, D., Wan, H., Fares, J. C., Meissner, A., Sumiyoshi, M., et al. (2015). Therapeutically targeting tumor necrosis factor-alpha/sphingosine-1phosphate signaling corrects myogenic reactivity in subarachnoid hemorrhage. Stroke 46, 2260-2270. doi: 10.1161/STROKEAHA.114.006365

Yamamoto, E., Yamashita, T., Tanaka, T., Kataoka, K., Tokutomi, Y., Lai, Z. F., et al. (2007). Pravastatin enhances beneficial effects of olmesartan on vascular injury of salt-sensitive hypertensive rats, via pleiotropic effects. Arterioscler. Thromb. Vasc. Biol. 27, 556-563. doi: 10.1161/01.ATV.0000254855.24394.f9

Yamamoto, H. A., and Mohanan, P. V. (2002). Melatonin attenuates brain mitochondria DNA damage induced by potassium cyanide in vivo and in vitro. Toxicology 179, 29-36. doi: 10.1016/S0300-483X(02)00244-5
Yang, Y., Sun, Y., Yi, W., Li, Y., Fan, C., Xin, Z., et al. (2014). A review of melatonin as a suitable antioxidant against myocardial ischemia-reperfusion injury and clinical heart diseases. J. Pineal Res. 57, 357-366. doi: 10.1111/jpi. 12175

Ye, Z. N., Wu, L. Y., Liu, J. P., Chen, Q., Zhang, X. S., Lu, Y., et al. (2018). Inhibition of leukotriene B4 synthesis protects against early brain injury possibly via reducing the neutrophil-generated inflammatory response and oxidative stress after subarachnoid hemorrhage in rats. Behav. Brain Res. 339, 19-27. doi: 10. 1016/j.bbr.2017.11.011

Zagorac, D., Yamaura, K., Zhang, C., Roman, R. J., and Harder, D. R. (2005). The effect of superoxide anion on autoregulation of cerebral blood flow. Stroke 36, 2589-2594. doi: 10.1161/01.STR.0000189997.84161.95

Zavodnik, I. B., Domanski, A. V., Lapshina, E. A., Bryszewska, M., and Reiter, R. J. (2006). Melatonin directly scavenges free radicals generated in red blood cells and a cell-free system: chemiluminescence measurements and theoretical calculations. Life Sci. 79, 391-400. doi: 10.1016/j.lfs.2006.01.030

Zhang, H. M., and Zhang, Y. (2014). Melatonin: a well-documented antioxidant with conditional pro-oxidant actions. J. Pineal Res. 57, 131-146. doi: 10.1111/ jpi.12162

Zhang, X. S., Li, W., Wu, Q., Wu, L. Y., Ye, Z. N., Liu, J. P., et al. (2016). Resveratrol attenuates acute inflammatory injury in experimental subarachnoid hemorrhage in rats via inhibition of TLR4 pathway. Int. J. Mol. Sci. 17:E1331. doi: 10.3390/ijms17081331

Zhang, Z. Y., Sun, B. L., Yang, M. F., Li, D. W., Fang, J., and Zhang, S. (2015). Carnosine attenuates early brain injury through its antioxidative and anti-apoptotic effects in a rat experimental subarachnoid hemorrhage model. Cell. Mol. Neurobiol. 35, 147-157. doi: 10.1007/s10571-0140106-1

Zhao, L., An, R., Yang, Y., Yang, X., Liu, H., Yue, L., et al. (2015). Melatonin alleviates brain injury in mice subjected to cecal ligation and puncture via attenuating inflammation, apoptosis, and oxidative stress: the role of SIRT1 signaling. J. Pineal Res. 59, 230-239. doi: 10.1111/jpi.12254

Zhao, L., Liu, H., Yue, L., Zhang, J., Li, X., Wang, B., et al. (2016). Melatonin attenuates early brain injury via the melatonin receptor/sirt1/NF-kappaB signaling pathway following subarachnoid hemorrhage in mice. Mol. Neurobiol. 54, 1612-1621. doi: 10.1007/s12035-016-9776-7

Conflict of Interest Statement: The authors declare that the research was conducted in the absence of any commercial or financial relationships that could be construed as a potential conflict of interest.

Copyright (c) 2018 Guo, Jin, Sun, Zhao, Liu, Ma, Sun and Yang. This is an open-access article distributed under the terms of the Creative Commons Attribution License (CC BY). The use, distribution or reproduction in other forums is permitted, provided the original author(s) and the copyright owner(s) are credited and that the original publication in this journal is cited, in accordance with accepted academic practice. No use, distribution or reproduction is permitted which does not comply with these terms. 